\title{
Basic Terminology of Landscaping: Sources and Contemporary Condition
}

\author{
Alexey O. Taranov ${ }^{1 *}$, Elena N. Taranova ${ }^{1}$, Ksenia A. Kolesnikova $^{2}$ Lyudmila I. Belousova $^{1}$, Tatiana N. Furmanova ${ }^{1}$ \\ ${ }^{1}$ Belgorod State University, 308015, Russia, Belgorod, Pobeda Street, 85 \\ ${ }^{2}$ Belgorod Law Institute of Ministry of the Internal of the RF named after I.D. Putilin, 308024, Belgorod, Gorky Street, 71
}

\begin{abstract}
The problem of interpreting and changing the meaning of terms is relevant in many sciences, including in linguistics. The authors touch on the problem of different interpretations of basic terms in the landscape studies. The article deals with the history of the origin of the terminological vocabulary of the landscape science, describes the problems associated with its use by specialists and the changing meanings of terms over the past decades. Whereas these terms are mostly used interchangeably, there are obviously some fine differences in meaning. In this paper, important moments of the scientific understanding of the basic terms of landscape are presented.
\end{abstract}

Keywords: terminology, terminology of the landscape science, a term, basic terms of the landscape science, interpretation of a term, changing the meaning of a term.

\section{Introduction}

Any term that designates a concept requires precise definition. The definition of the term should be sufficient, exhaustive and limit this concept from other concepts. This also applies to the terminology of landscape studies. Today in modern landscape science there is still the problem of unambiguous interpretation of terms, as well as the existence of several terms for designating the same concept. So, for example, the term "landscape" is still defined in different ways.

\section{Methods}

Methods of the analysis are defined by objectives, a theoretical and practical orientation of the research, and a character of the presented material. In the paper the authors implied various types of the analysis: the theoretical and analytical method, the complex method, the method of analysis of vocabulary definitions.

\section{Results and Discussion}

When creating a scientific picture of the world, scientists must base their ideas on clearer definitions of the terms that they use in their scientific activities. In landscape science, like other sciences, terminology is of great importance. Any term that designates a concept requires a precise definition. The definition of a term should be sufficient, exhaustive and delimit this concept from other concepts.

On the other hand, an unambiguous use of the term is equally important. Unfortunately, it so happened that in the Russian language, as in others, many terms are used in different branches in different meanings. This also applies to the terminology of landscape studies. Usually the discrepancies in the definition of the terms of a certain branch of science are associated with its rapid development.
The basic term of science "landscape science" is the term "landscape", which in addition occurs in various spheres of life: everyday life, art, science. The history of its meanings changing over the past few decades, especially in Soviet and post-Soviet geography, has proved to be very difficult. There are many scientific definitions of the term "landscape". This circumstance indicates that its essence is very complicated.

Originally the term appeared in connection with its first landscape- interpretation. The notion of "landscape" among nonspecialists landscape experts in colloquial and literary language is used rather with an emotional tinge: "beautiful", "dull", "gracious", etc. and denotes a landscape, a picture of nature, a locality, etc. [7].

Later, the term "landscape" was borrowed by complex physical geography to denote a special class of objects of research. In this connection, the term "natural-geographical landscape" appears. The term was entrenched and entered the title of the special area of physical geography "landscape science". The geographical concept of "landscape" is broader and more precise - a natural geographic complex within which all-natural components, as well as artificial ones, are in complex interaction and adapted to each other, forming the structure of a single system; therefore, a landscape approach is, first of all, a systemic approach [3].

If in the pre-revolutionary period the meaning of the term practically did not differ from its ordinary understanding and meant a kind of terrain, landscape (in this meaning it was recorded in the BED and in the Explanatory Dictionary of the Russian Language by Ozhegov, 1949), since 1914 after the appearance of the famous work of L. S. Berg, this term was given a completely different meaning, which was associated with the idea of the socalled geographical complex (in the understanding of L.S. Berg 1947) [1].

It is well known that L.S. Berg first gave a scientific definition of the concept of "landscape" in 1913. Berg defined a landscape as: "that combination or grouping of objects and phenomena in which 
the peculiarities of relief, climate, water, soil, vegetation and fauna, and to a certain degree human activity, blend into a single harmonious whole, typically repeated over the extent of the given zones of the Earth." [1]. The scientist conducted a zoning of the entire territory of Russia, where for the first time the zones established by him were called landscape ones. He introduced the division of landscapes into natural and cultural ones.

At this time, most Russian and Western geography scientists meant by a landscape the general appearance of the terrain. L.S. Berg himself also used this interpretation of the term, however, as for the term "landscape", L. S. Berg, in his understanding of the term, rejected the etymology of the word, which, according to a number of geographers, is completely unacceptable.

It is known that the term "landscape" was introduced into the geographical science during the Renaissance in terms of the natural background in the paintings of artists. Under the term "relief", which is so interpreted to this day, they understand a certain configuration with respect to the background surface. Such a background surface can be any smooth surface. The relief is an organic part of the landscape.

If you turn to the Great Soviet Encyclopedia, edition 2, volume 24 [4], there are two articles devoted to the landscape in it. In the first article, "landscape" is a scenery. The second article gives a scientific definition of the term "landscape". Thus, we can conclude that the term has two interpretations: naive (profane) and scientific. As a naive interpretation, "a landscape is a kind of terrain." And in this definition there is nothing that can be subjected to scientific research. A completely different situation arises with a scientific interpretation that allows us to proceed from the fact that the landscape is a certain geosystem that in its different parts is in different regimes connected by marginal zones.

According to scientists, the word "landscape" (like the relief) - a sculptural reflection on the plane, which came from the sphere of art, is already endowed with a meaning that cannot be changed. Such concepts as "landscape" unite science and art. If we make a comparative analysis of the interpretation of the term in other encyclopedic publications, we can note its discrepancy in Russian and foreign scientific works. So, in the 30-volume American Encyclopedia, the term "landscape" is associated with art - the image in paintings and landscape design [2].

The term "landscape", as analysis of special scientific literature shows, to the present day continues to be controversial for many geographers in their definition in landscape studies. Its interpretation within the framework of structural and genetic landscape studies and in its natural interpretation raises heated discussions. They concern the content and use of the concept of "landscape" and are not in the last place in publications on the theory of geography.

One and the same word "landscape" in different scientific directions is used to denote various phenomena. Namely: the landscape - as an organization of the drawing of the day surface, perceived by the subject [5]; landscape as a synonym for a naturalterritorial complex or a geosystem of any dimension (from a swampy mound and to a landscape envelope) - a broad interpretation of the term "landscape" within the framework of landscape studies; landscape - as a natural and territorial complex of regional dimension with the regular repetition of the same interconnected and interdependent combinations of natural components (the upper part of the earth's crust, water, surface air, flora and fauna) within the framework of the regional interpretation of the term in the line facies - tract - terrain landscape - province.

The discrepancy in the interpretation of the term "landscape" led to the discussion of the possibility of replacing the term "landscape" with the term "berg-layer", proceeding from the fact that what is meant by "landscape" refers to the scientific interpretation of this term by L. S. Berg. But, according to scientists geographers, this replacement is not constructive. The word "landscape" has already taken root in landscape studies and its replacement will lead to even greater misunderstanding of it. Along with the different interpretation of the term "landscape" in Russian landscape studies, there are a number of other terms that are also concerned with the problem of changing the meaning of understanding. These terms include, for example, the term "facies". A related term is the term "situation", which reflects the relationship between some object and its environment. "Facies" is not a material object, but an image of the situation that reflects the connection of a genetically homogeneous territorial geocomplex. As for other terms, among geographers there are reproaches in the misuse of terms borrowed from other sciences. So, for example, the word "soil", like the word "landscape", before the advent of the science of "landscape studies" was used in completely different ways. Up till now, for the common people, "soil" is "ground", "mud", "base". Let us consider the meaning of this word in dictionaries.

In the Geographical Encyclopedic Dictionary [3]: "SOIL, a natural formation consisting of genetically related horizons formed as a result of transformation of the surface layers of the lithosphere under the influence of water, air and living organisms; has fertility. It consists of solid, liquid (soil solution), gaseous and live (soil fauna and flora) parts. It is subdivided into genetic types (e. g., podzolic, gray forest, chernozem, serozem). The geographical distribution of soils on the plains is subject to the general laws of latitudinal zoning, and in the mountains - to vertical zonality. In agriculture - the main means of production".

The Modern Explanatory Dictionary of the Russian Language by T. Efremova - "soil" (1) The surface layer of the earth's crust, in which plant life develops. (2) fig. foundation, support. (3) The rock on which the mineral deposits [10].

The term "anthropogenic landscapes" also has several definitions. Thus, "anthropogenic landscapes" are complexes in which, if not all, at least one of the components of the landscape, including vegetation, has undergone a radical change under the influence of man. A similar treatment of anthropogenic landscape was adopted in the international dictionary "Protection of landscapes. Explanatory dictionary" [6] and in "Geographical encyclopedic dictionary. Concepts and terms" (1988) [3]. Attempts by some authors to replace the notion of anthropogenic landscape with an "anthropogenized" or "anthropicized" landscape have not been widely supported. In the noospheric stage of development of the landscape sphere, all landscapes of the Earth are to some extent anthropogenized.

Another definition of anthropogenic landscape is given by A.M. Ryabchikov, "man-made landscape" - not a new complex, but only a slight change in the old one, according to the "Explanatory dictionary of the Russian language", modify means "to bring (modify) something into something, without transforming the inner essence of the object" [8].

The representation of the same concept by a series of definitions from different sources reflects the diffuse nature of the concept's intension. Each scientist has his own ideology of perception of the precise concept, singling out not only established parameters in it, but also those aspects on which he focuses his attention for a reason known only to the author of the description [9].

\section{Conclusion}

"Landscape" is a term used by several disciplines, including fine arts, landscape architecture and geography. There are many different interpretations of the term "landscape". The disparity in definitions makes it difficult to communicate clearly. Definitions of the landscape invariably include an area of land containing a mosaic of patches or landscape elements.

This article clearly demonstrates that problems in the field of landscape terminology pose the topical tasks that need to be solved today. And first of all it concerns the defending of the landscape terminology in its basic structural-genetic understanding 
and the creation of a vocabulary of terms (paper and electronic) in order to facilitate understanding of the content of the basic terms.

In many meanings applied to the word "landscape" there is no single, commonly agreed interpretation.

\section{References}

[1] L. Berg, Climate and life (2nd ed.), Geografgiz, Moscow, 1947.

[2] Encyclopedia Americana, Grolier, International edition, 1992.

[3] Geographical encyclopedic dictionary. Concepts and terms, Publishing house Great Soviet Encyclopedia, Moscow, 1988.

[4] Great Soviet Encyclopedia, 2nd ed., vol. 24. 1949-1960. Moscow: Publishing house Great Soviet Encyclopedia.

[5] A. Kovalev, Landscape itself and for the human, Burun Book, Kharkov, 2009.

[6] Protection of landscapes. Explanatory dictionary, Progress, Moscow, 1982.

[7] N. Reimers, Nature management. Dictionary-reference book, Thought, Moscow, 1990.

[8] A. Ryabchikov, The main features of the development of the geosphere and the planetary differentiation of its landscapes: Physical geography of continents and oceans, Moscow, 1988.

[9] V. Tatarinov, Terminological vocabulary of the Russian language: the evolution of problems and aspects: Russian language in modern society: functional and status characteristics, INION RAS, Moscow, 2006.

[10] T. Yefremova, Modern explanatory dictionary of Russian language. In 3 Vols., AST, Moscow, 2006. 